\title{
The nature of confidentiality*
}

\author{
Ian E Thompson Edinburgh Medical Group Research Project in Medical Ethics and Education. \\ University of Edinburgh, Edinburgh
}

This paper examines confidentiality and its nature and analyses the guidelines laid down by the Hippocratic Oath as well as the British and World Medical Associations for maintaining such confidentiality between doctor and patient.

There are exceptions to practically any code of rules and this is true also for confidentiality. Some of these exceptions make it appear that very little is confidential.

The three values implicit in confidentiality would seem to be privacy, confidence and secrecy. Each of these values is discussed and developed in this paper. In conclusion, the question is suggested that maybe in the face of death, doctor and patient need to re-examine the pre-suppositions of privacy, confidence and secrecy on which the confidential relationship is based.

\section{A question of confidentiality}

Why is confidentiality so important or valuable in itself ? Most of the available professional codes do not answer this question. They assume that the value of confidentiality is self-evident, and do not seriously examine the grounds for maintaining relationships of confidentiality, nor do they provide adequate moral or philosophical justification for doing so.

It is customary to point to the Hippocratic Oath and then to imply that its provisions have governed doctor-patient relationships since the 5 th century BC. For example, the BMA handbook on Medical Ethics ${ }^{1}$ begins with an appeal to the Oath as a foundation for medical ethics. In a recent statement on confidentiality the Royal College of Psychiatrists asserts:

One of the few provisions of the Hippocratic Oath which has remained unaltered over nearly 3,000 years is that relating to confidentiality:

'And whatsoever I shall see or hear in the course of my profession, as well as outside my profession in my intercourse with men, if it be what should not be published abroad, I will never divulge, holding such things to be holy secrets.'

The undertaking is repeated in the Declaration of Geneva:

*This paper was first delivered to a conference of the Royal College of Psychiatrists (Scottish Division) in September 1977.
'I will respect the secrets which are confided in me, even after the patient has died.' ${ }^{2}$

This appeal to the ' 3,000 year-old tradition of the Hippocratic Oath' is not historically justified, because the Oath has not been a regular or constant basis of medical practice through the ages. We should remember that the oath originated in what was an esoteric cult, and the obligations of secrecy were as much concerned with protecting trade secrets and maintaining control over initiates as they were concerned with the patient's interest. (It might be remarked in passing that it is always as much in the practitioner's as the patient's interest to maintain relationships of confidentiality, especially in private practice). In fact, the Oath only applied to the Hippocratic School and there were other schools in antiquity without such requirements. With the establishment of the mediaeval universities and faculties of medicine, and with the attempts by Roger II of Sicily in I 140 and Frederick II in 1224 to control and regulate healing practices by legislation, new interest in the Oath was shown by certain guilds of physicians. However, its use never became general. It was only during the late eighteenth and early nineteenth centuries, when physicians and surgeons were struggling to achieve recognition as professionals in their own right, that the demand for an explicit code of professional practice became important. ${ }^{3}$ The Hippocratic Oath thus came to be adopted as the trademark of the Victorian doctor, as physicians and surgeons buried the hatchet and turned to more subtle forms of internecine conflict. One of the paradoxes faced by modern medicine and one of the reasons why the Hippocratic Oath has had to be qualified by so many other Codes and Declarations, is that modern medicine is built not on secrecy and rites of initiation, but on exoteric scientific knowledge, on free publication and open access to the results of medical research. These developments now compel us to re-examine the grounds for confidentiality.

\section{Is there a principle of confidentiality?}

The I974 BMA handbook on Medical Ethics boldly reaffirms the doctor's obligation to maintain secrecy in what appear to be most uncompromising terms:

It is a doctor's duty strictly to observe the rule of professional secrecy by refraining from disclosing 
voluntarily to any third party, information which he has learned directly or indirectly in his professional relationship with the patient. The death of the patient does not absolve the doctor from the obligation to maintain secrecy. ${ }^{4}$

However, there immediately follow a list of five kinds of exception:

The exceptions to the general principle are:

a) the patient or his legal adviser gives valid consent

b) the information is required by law

c) the information regarding a patient's health is given in confidence to a relative or other appropriate person, in circumstances where the doctor believes it undesirable on medical grounds to seek the patient's consent

d) rarely, the public interest may persuade the doctor that his duty to the community may override his duty to maintain his patient's confidence;

e) information may be disclosed for the purposes of any medical research project specifically approved for such exception by the BMA including information on cancer registration. ${ }^{5}$

What, one might ask, remains of the patient's right to privacy if the doctor's discretion is so large? If it were not in the doctor's own interest to maintain relationships of confidentiality, one wonders if the reaffirmation of the patient's right to privacy would amount to more than pious rhetoric.

It is significant that except in the case of the doctor being required by law to disclose information in court, the other caveats offered serve to emphasise either the autonomy of the medical profession in deciding what is in the common good (in matters relating to Public Health, Medical Research and Health Service Planning), or in emphasising the doctor's right to independent clinical judgement, (in situations where he considers it undesirable to seek the patient's consent to disclose information).

The point at issue is not whether the medical profession should be an autonomous self-regulating body, nor is it a matter of undermining or attacking the doctor's clinical judgement. The question is whether confidentiality is a matter of principle or a matter of practical medical expediency. Is there really a 'principle of confidentiality' as the BMA asserts? If so, why do more doctors not go to prison rather than divulge professional secrets? Is a person entitled to privacy as a 'right'? In certain circumstances that right is enforceable in a court of law - in the sense that an injured party can seek legal redress for the public disclosure of confidential information. However, what kind of right is it, and what weight should it be given in relation to other rights? Is it an unconditional moral right? Should the privilege of withholding confidential information which applies in this country only to lawyers, and in certain circumstances to priests, b\& extended to doctors?

These are some of the questions which should be considered if confidentiality is a matter of strice principle rather than conventional and usefut practice. In what follows an attempt is made to clarify some of the values on which it might be possible to argue that there is a principle at stake when matters of confidentiality arise.

\section{Privacy, confidence, and secrecy: three values implicit in confidentiality}

The World Medical Association resolutions of 'Medical Secrecy' and on 'Computers in Medicine provide us with as near as we can get to a explicio statement of the values underlying the concept of confidentiality:

Whereas: The privacy of the individual is highl prized in most societies and widely accepted as civil right; and

Whereas: the confidential nature of the patient doctor relationship is regarded by most doctors. as extremely important and is taken for grantee by the patient; and

Whereas: there is an increasing tendency towardf an intrusion on medical secrecy;

Therefore be it resolved that the 27th World Medici Assembly reaffirm the vital importance of maintaining medical secrecy not as a privileg\& for the doctor, but to protect the privacy of thet individual as the basis for the confidentiat relationship between the patient and his doctor? and ask the United Nations, representing the people of the world, to give to the medical pros fession the needed help and to show ways fo securing this fundamental right for the individua human being. ${ }^{6}$

This resolution, anticipating as it does the possible abuse of data storage and retrieval systems to invade the privacy of individuals and greater state control of the lives of individuals, particularly totalitarian states, enunciates three values implicit. in confidentiality:

I) Privacy: The right of the individual to privacys

2) Confidence: The necessary ground of the doctor/patient relationship or contract.

3) Secrecy: The doctor's right to independen clinical judgement, and the question of truthfulnes in inter-personal relations.

PRIVACY: THE SCOPE AND LIMITS OF THE RIGHT T\&े PRIVACY

We may all agree that there is an implicit threat t\& individual liberty in modern increasingly centralised and technocratic societies. These dangers can be seen in modern technological developments such as computer storage of information, techniques of 
photocopying, and the invasion of personal privacy by the mass media. However, we may still ask: Is there a right to privacy?

For personal reasons we may feel that privacy is important, but is it a moral right? For practical reasons (Public Health, Research Interests, Health Service Planning) medical confidentiality can be overruled. For political ends the state may decide to abrogate an individual's so-called 'right to privacy'.

The 'right to privacy' might well be regarded by many as a device of medical/political rhetoric or an impractical ideal, but on logical grounds, if we concede the existence of individual human rights of any kind, then it is almost tautologically selfevident that there must be a 'right to privacy' for without it there would be no private individuals to have or exercise those rights. That the individual should be spiritually inviolate, in the sense of being protected from the invasion, violation and abuse of his privacy would seem to be the necessary presupposition of his possession of any of the other individual human rights claimed for him, eg the right to freedom of speech, freedom of movement and association, freedom of worship etc. We must, I think, grant the existence of a right to privacy on formal grounds once we concede the existence of personal rights in any form. Since it is not our purpose to dispute that, the question becomes one of interpreting the scope and limits of the right to privacy.

The moral situation in which patient and doctor encounter one another is one which gives to privacy a special value, confidential privacy is inherent in the situation as a moral pre-supposition for at least three reasons:

I) The patient approaches the doctor under duress of fear, pain or need. This means that the patient is inherently vulnerable and disadvantaged in relation to the doctor. The 'contract' between them is not a contract as between equals (hence it maybe misleading to speak as some sociologists do of patients as 'consumers'). The patient is a patient (ie a sufferer), a person who may well be conforming to the sick role, but whose disease has forced him to accept the limitations and obligations of that role as well as its possible advantages. The moral responsibility of the doctor in the first instance is to respect the vulnerability of the 'patient'; his privacy in this sense.

2) The fact that the doctor is a member of a consulting and not just scholarly profession, means that 'patients' come to him in situations which are of their very nature private, in the consulting room or the relative privacy possible in the hospital ward. The contract to enter into the secrecy of a private consultation implies obligations binding really on both parties, especially where the relationship is one of co-operation based on the acceptance of the authority of one party to guide or even direct the performance of unusual acts (eg getting undressed, allowing examination of intimate parts, disclosing ntimate information.)

3) The sharing of intimate information in the activity of truth-telling, involves the implicit rules of reciprocal confidence, otherwise the process could not get started. Violation of confidence does not just involve an infringement of a rule of procedure as if it were a game which does not matter crucially (like admissible cheating in poker). It contradicts the possibility of the 'game' itself. This is why both parties to a broken confidential relationship feel mortally wounded.

These factors of initial vulnerability, voluntary self-exposure and confidence-sharing create special obligations in the one to whom these gestures of intimacy and private self-revelation are made. We implicitly recognise this when we discourage importunate people from unburdening themselves to us. They not only demand our attention but impose unwelcome obligations on us.

Areas of medicine where respect for the 'right to privacy' would appear to be particularly important are psychiatry and reproductive medicine. In psychiatry the issue of privacy is important because of the peculiar vulnerability of the mentally ill, because of the probing nature of psychiatric investigations of people's psycho-sexual behaviour and problems of social adjustment, and because of the considerable stigma still associated with mental illness. The information elicited in the course of psychiatric treatment makes the patient extremely vulnerable to both psychological manipulation and criminal blackmail (if the information falls into the wrong hands). In reproductive medicine, in the treatment of gynaecological disorders, male infertility and venereal disease, the issue of privacy is important in relation to the prevailing attitudes and feelings of shame about sexual matters. While these may be culture-dependent and culture-specific, nevertheless taboos and feelings of shame are common to all societies in relation to different things for different people, and the right to privacy remains important in relation to these feelings.

The stigma of illness is not just imposed by society nor just by the medical profession, but more fundamentally, as Bonhoeffer ${ }^{7}$ has suggested by shame, ie an awareness of injury, lack of health, wholeness or spiritual dis-ease:

The peculiar fact that we lower our eyes when a stranger's eye meets our gaze is not a sign of remorse for a fault, but a sign of shame which, when it knows that it is seen, is reminded of something it lacks, namely, the lost wholeness of life, its own nakedness. . . .

The dialectic of concealment and exposure is only a sign of shame. Yet shame is not overcome by it; 
it is rather confirmed by it. Shame can only be overcome when the original unity is restored.

In both medicine and religion, there tends to be a tension between ideals of openness and attempts to defend the need for privacy. On the one hand medicine purports to be scientific in the sense that it is based on public and verifiable facts, exoteric knowledge and free exchange of research findings. On the other hand medicine, as a consulting profession recognises in clinical relationships with patients their vulnerability and need for privacy. In religion the more the stress has been placed on the sinful and alienated nature of man, the more the need for privacy in spiritual matters has been emphasised. On the other hand the Christian ideal of an open society, where men will not be afraid to 'live in the light' or have their deeds 'shouted from the rooftops', is based on an expectation of a redeemed society. Both medicine and religion face painful dilemmas where these values conflict.

In wider society, to the extent that we value justice, democratic government and scientific progress, privacy cannot be an absolute or unconditional right; but, to the extent that we recognise the presence in society and its institutions of forces which are destructive of justice, democracy and scientific progress, we must also take account of the importance of the right to privacy to protect vulnerable people. The limits to the right to privacy are illustrated in the controversy over Lord Moran's disclosures, in his biography of Churchill, of details of the strokes and other illnesses which he suffered while in office.

Robitscher ${ }^{8}$ points to the potentially dangerous consequences of impaired judgement resulting from Churchill's illnesses. He not only questions the implied condemnation of Lord Moran expressed in a contemporary editorial in the Lancet and the BMA resolution that the 'death of a patient does not absolve the doctor from his obligation of secrecy', but asks whether the physicians in question did not have a public duty to make this information known when he was alive and possibly to put pressure on their illustrious patient to resign. He suggests two tests concerning disclosure:

I) Was something disclosed to the confidant in the course of and as an important part of securing help or treatment which would not have been disclosed except in the process of gaining help?

2) Was the information, if divulged, "fitting to be spoken'?

\section{He concludes:}

The physician is not only a doctor to his patient, but he also fulfils a public role, he gives reassurance to the public concerning the health of its elected officials. I submit that under such circumstances there can be justifiable exceptions to the principle that the patient's state of health is a private rathero than a public matter.

Another reviewer whom he quotes put it morẹ dramatically:

... a figure such as Churchill cannot have anyo privacy. He belongs to the world, alive or dead, and anything related to him, especially his health problems, are of universal interest.

The fact is that privacy is a relative state and one of the things that public figures sacrifice for the dubious benefits of political popularity or stardom is their right to privacy. The choice of a career ing public office means the necessary exposure of you life to public scrutiny, and while decency anథ decorum, and the laws of libel may set some limitir to public exposure, the public interest must in mant cases take precedence over the right to privacy where public security and the demands of justice require it.

CONFIDENCE: THE NECESSARY GROUND OF THE PATIENT/DOCTOR RELATIONSHIP OR CONTRACT $\vec{\bullet}$ The second value implicit in confidentiality iș confidence itself. This is not just a desirable cone commitant of medical practice, but an essentias moral pre-requisite of the contractual relationshis into which patient and doctor enter.

At the practical level, as Balint ${ }^{9}$ suggests, 'th efficacy of the drug: Doctor' depends upon it. great deal of the efficacy of medicine depends of 'the placebo effect', the ability of the doctor to win the confidence and trust of the patient and tof maintain it often for many years.

However, this confidence (cum-fides) is not jus desirable for its therapeutic benefits, it is essential pre-supposition of the contract of operation in mutual truthfulness into which doctos and patient enter. Whereas privacy is primarily in the patient's interest, confidence is in the mutuad interest of the contracting parties. It is the ex pression of willingness to enter into the con? tractual relationship, of the patient's willingness t submit to the doctor's authority and of the doctor XS willingness to attend to the patient's needs to the best of his ability. The relationship is not estabs lished once and for all, and, as Balint has suggesteds the doctor and patient are involved in an on-going negotiation of the limits of their confidential rec lationship and the limits of truthfulness or opennes? in that relationship through a series of symptomso offered by the patient and responses by the doctori Or, as Friedson ${ }^{10}$ says:

The patient, for instance, is likely to want more information than the doctor is willing to give him more precise prognoses, for example, and mor8 precise instructions. Just as the doctor struggles find ways of withholding some kinds of information 
so will the patient be struggling to find ways of gaining access to, or inferring such information. Similarly, just as the doctor has no alternative but to handle his cases conventionally (which is to say, soundly), so the patient will be struggling to determine whether or not he is the exception to the conventional rules.

In the conflict/co-operation underlying doctorpatient interaction, mutual confidence is a necessary prerequisite. Distrust on either side is enough to bring a relationship to an abrupt end. Insofar as confidence in this situation is essential to the functioning of the relationship, implicit respect for mutual confidences is implied. However, the nature, form and limits of that confidentiality may not be specified or explicit and perhaps ought to be negotiated more explicitly.

It is generally maintained, especially by doctors and in the pious or indignant statements issued by their professional associations, that confidentiality is maintained primarily in the patient's interest. This assumption needs to be questioned if we are to get beneath the surface of the public rhetoric and consider more seriously the practical value and moral significance of confidentiality. The secret of the doctor's power over his patient lies precisely in his possession of what is often vital confidential information (at least in the patient's view). Medical pieties about confidentiality might be more convincing if doctors were more candid about the part played in the 'management' of patients by the control and selective disclosure of information. It is also evident in the inter-collegial and interprofessional dealings of the doctor that the selective disclosure of confidential information is used by the doctor both to assert and maintain control over 'his' patients. The making of referrals is obviously a game requiring great skill or art, both when it involves defining limits to responsibility for individual patients, and when it involves 'passing the buck'. The cruder forms of this exploitation of confidental information to maintain control of patients are perhaps more obvious in a situation of fee-paying private medicine, but they operate none the less in the NHS too.

To put the issue into perspective it is perhaps necessary to stop and ask: whose confidences are they, anyway ? In a sense the question has a simple answer: they are the patient's confidences and that is why the doctor has no moral right to use confidential information without the consent of the patient or in the patient's interest.

A radical expression of this point of view, and a serious attempt to discuss and analyse its implications for medical practice, is the important article by Shenkin and Warner entitled 'Giving the patient his medical record: a proposal to improve the system'. They argue that giving the patient his medical record would: a) provide the patient with better and more reliable information,

b) lead to better patient compliance with medical advice,

c) serve as an educational tool and,

d) encourage the patient to accept more responsibility for his own health.

Further they argue that this would mean better continuity in patient-care in an increasingly mobile population, enable the patient to exercise wider freedom in the choice of medical practitioners and consultants, and improve physician-patient relations by making the relationship dependent on more rational negotiation of contracts.

The advantages to physicians of such an arrangement would be, they argue, that it would have the effect of promoting more regular and formal, though decentralised peer review, encourage doctors to keep up to date and learn from one another. They also claim this would lead to greater career satisfaction, as such decentralised peer review would provide recognition for excellence in the practice of medicine rather than merely emphasise the prestige of sophisticated research and high technology medicine as the present system tends to do. It would also work to support the autonomy of the physician and militate against the tendency to centralised bureaucracy in health-care systems:

Adopting the Proposal would reduce fears about physician accountability and quality. Self-regulating, decentralised peer review would provide better individual assessments than centralised review, since reviewers could correlate the patient himself with his record, instead of merely checking its internal consistency. Both inpatient and outpatient records would be used, and information would be generated precisely at the points of usage - patients and colleague physicians. On the other hand, some functions of centralised peer review, such as standard setting, would not be pre-empted. ${ }^{11}$

The situation in modern health-care, whether in the USA or the UK is one of increasing involvement of other professionals and para-professionals and changing patterns of inter-professional relationships. Whether in the technologically sophisticated areas of hospital medicine, involving many specialties, or in the primary medical care-team, there is, a situation of increasingly extended confidence.

Whether we go along with this and accept the fact that in the Welfare State with a National Health Service there is an inevitable need for the dilution of confidentiality, in the interests of efficient patient-care, systematic medical research, effective public health programmes and more rational health service planning; or whether we opt for a system which re-inforces patients's rights and physician autonomy, say by giving patients their medical records, or reinforcing medical privilege in 
relation to confidential information, involves not just the moral issue of patients' rights versus public interest, but, more fundamentally, choices about what kind of society we wish to live in. It may well be too, that what is at issue in the present debate about confidentiality concerns the very nature of medicine as a profession: Is medicine to remain a consulting profession based on confidentiality, patient trust and medical autonomy and responsibility ?; or is the doctor to become a paid functionary in an impersonal institution where industrial action is compatible with offering medical services to the public?

The case of Dr R J D Browne illustrates one side of the problem. He was charged with improperly disclosing to the father of a girl then aged 16 that she had been prescribed an oral contraceptive by Birmingham Brook Advisory Centre. In a $B M F$ editorial ${ }^{12}$ the dismissal of the charges against $\mathrm{Dr}$ Browne by the General Medical Council Disciplinary Committee was hailed as triumphant reaffirmation of:

the principles of medical practice that the doctor has an obligation to act in the way he judges to be in the best interests of his patient.

Given the fact that Dr Browne thought it medically inadvisable for his patient to be given the particular oral contraceptive in question, it is argued that he was acting properly to inform the girl's father.

In a later issue of the $B M \mathcal{F}^{13}$ a senior barrister has argued that the $B M F$ editorial's argument does not hold, that legally Dr Browne had no right to violate his patient's confidence. He accuses the medical profession in effect of closing ranks over the defence of one of their colleagues and the sacrosanct principle of the independence of the doctor's clinical judgement.

There is a public dimension to confidentiality too, the question of the public confidence in the profession. The crisis of identity through which the profession is passing as well as a possible crisis of confidence in the medical profession expressed by increasingly strident public criticism of doctors, argues the need for the profession to renegotiate its contract with the public if confidence is to be restored. The BMA in its Handbook on Medical Ethics, tends to be rather arrogant about the ethical standards and traditions of medicine and rather dismissive of social work and other professions. However, the present situation in medicine with regard to confidentiality might well be illuminated by consideration of the example of social work. ${ }^{14}$

Because the status of social work as a profession is still disputed and uncertain and because it is notoriously difficult to set limits to the social worker's task and responsibilities, it has proved necessary in practice for social workers to negotiate fairly explicit contracts with their clients. Likewise, because the social worker has to act as a go-between and advocate on behalf of the client in so mant situations (as between client and local authority hospital, police, etc.) and as an agent of the Courts: or the hospital in other situations, it has prove雨 necessary for him to negotiate very carefully the bounds of confidentiality in his dealings wit clients and on behalf of clients.

Between the extremes of paternalistic an $\bar{\phi}$ authoritarian medicine, on the one hand, where the doctor decides on the control and appropriate disclosure of information; and the liberal alternativ of giving the patient his medical record and treating the patient's right to decide on the limits of conङ fidentiality as sacrosanct, there stands what I woulf call the social work model. This model has severaP advantages: it is flexible and adaptable to the needs of different people and patients with different kindo of complaints; it is based on a more open and democratic procedure; it allows due respect for the patient's rights but also leaves scope for the dise cretion and independent judgement of the doctor While it does expose the patient to the risk of undue pressure the demand that the limits of confidentiality should be explicitly determine within the confidential relationship itself rather than by external formal rules means that the process ought to be self-regulating and self-correcting subject only to the demands of accountability befor\& the courts and the laws of libel. It means that the doctor or other professional becomes not simpl the patient's representative but also society's representative in representing to the patient the demands of the common good - where the dis closure of confidential information may be benefit to others besides himself.

All the authorities seem to agree that the traditional safeguards against breaches of con fidentiality which operated fairly successfully in the patient/family-practitioner situation, do no work adequately in modern hospitals and in creasingly socialised medicine. It is arguables therefore that the mutual interests of patient and doctor could best be served by more open and explicit discussion of the limits of confidentiality (the determination of what bits are confidential and which are not) so that both know where they standw and by an extension to doctors of the privilege which applies to lawyers when the issue is the disclosure of proscribed bits of information. It i $\$$ not enough to speculate that patients would objecf to the disclosure of particular bits of information. The experience of social workers suggests that there is relatively little that clients regard as strictlip confidential. Most of what is required for efficieng health service planning, medical research, etc. canow be obtained, it is suggested, without too muck difficulty; but when confidentiality is important it if crucially important, and should be recognised as. such. The vital issue is to determine when it 
really important, and can only be breached with grave consequences for patient/doctor trust and with damaging consequences for the patient.

\section{SECRECY: THE DOCTOR'S RIGHT TO INDEPENDENT} CLINICAL JUDGEMENT

In the introduction it was suggested that secrecy should be included among the values implicit in confidentiality. It may well be asked, however, whether secrecy can be regarded as an end in itself or merely as a means to an end. In earlier times when medical and psychiatric knowledge was more insecure, and uncertain of its scientific base, members of the profession relied more explicitly on secrecy. In fact, it might be suggested that the more uncertainty, the more secrecy tends to surround that area of medicine, not only to protect the doctor but to protect the patient from his ignorance.

However, it is arguable that there is and will remain a perennial tension in medicine between the esoteric 'cultic' aspect of medicine and the public exoteric and scientific aspect, between the saving, redemptive aspects of medicine and those aspects concerned with knowledge, prediction and control of the disorders of human life. On the one hand, the doctor's secrets, both his knowledge of the mysteries of medicine and his knowledge of the intimacies of his patients' lives, is the secret of his power. On the other hand, it is also the basis of his claim to autonomy in the exercise of his clinical judgement, knowledge and expertise, and familiarity with the needs of his patient. The aura of secrecy also serves to create patient dependence and compliance, defines the boundaries of the sick role and creates the need for appropriate magic, whether in the form of physical procedures or drugs. However it also conveys a residual feeling of suspicion which can erupt into an 'anti-clerical' backlash against the whole medical establishment.

Medical science in its public and exoteric character has a double effect on public attitudes. On the one hand, more general education of the public in scientific and medical matters creates pressure towards the democratisation of health-care, suggests the possible liberation of patients from doctor-dependence and creates the demand for a new contract between the medical profession and the public based on respect for patients' rights. On the other hand, the claim of medicine to be scientific, to be able to discover and explain the causes of disease, to predict and control their consequences, creates the spiral of rising expectations that medicine will be able to cure all humanity's ills. Both tendencies unfortunately often lead to increasing public scepticism and disillusionment and to an increase in 'doctor bashing'. The disappointment of public hopes in psychiatry seem to be a particular case in point.

The dialectic of secrecy and openness in medicine is obviously part of the practical situation we have to take into account, but it does not illustrate how secrecy might be regarded as a value in its own right. Part of the difficulty is that we tend to invest secrecy in general with a negative value, even implying that it is synonymous with deceit. This is because we tend to apply the paradigm of scientific truth inappropriately to personal relationships, and uncritically accept the rationalist and liberal ideal of openness as the norm of behaviour for professional relationships. Science is concerned with the abstract and impersonal relationships of facts and propositions. Medicine, insofar as it is a human science is concerned with the degrees of truthfulness possible in different kinds of personal relationships. Secrecy and truthfulness stand in a different relationship from truth and falsity, truth and error or truth and deceit. While truth and falsity apply to statements, truth and error to man's practical judgements and actions, truthfulness and deceit apply to the subtle inter-actions of persons in confidential relationships. In a brilliant essay on 'What is meant by "telling the truth" ?' Bonhoeffer ${ }^{15}$ suggests that it is only the cynic who claims "to speak the truth" at all times and in all places to all men in the same way' and that in reality such an attitude is destructive of the living truth between men:

He wounds shame, desecrates mystery, breaks confidence, betrays the community in which he lives, and laughs arrogantly at the devastation he has wrought and at the human weakness which 'cannot bear the truth'.

Secrecy is not the enemy of truthfulness but the companion and guardian of truthfulness as we explore the possibilities for truthfulness in a given situation. Secrecy from this point of view has a value because it has an intimate relationship with the determination of the truth in each unique human situation and the expression of truthfulness in personal relationships:

From the moment in our lives at which we learn to speak we are taught that what we say must be true ... It is clear that in the first place it is our parents who regulate our relation to themselves by this demand for truthfulness; consequently, in the sense in which our parents intend it, this demand applies strictly only within the family circle. It is also to be noted that the relation which is expressed in this demand cannot simply be reversed. The truthfulness of a child towards his parents is essentially different from that of the parents towards their child. The life of the small child lies open before the parents, and what the child says should reveal to them everything that is hidden and secret, but in the converse relationship this cannot possibly be the case. Consequently, in the matter of truthfulness, the parents' claim on the child is different from the child's claim on the parents. 
From this it emerges already that 'telling the truth' means something different according to the particular situation in which one stands. Account must be taken of one's relationships at each particular time. The question must be asked whether and in what way a man is entitled to demand truthful speech of others. Speech between parents and children is, in the nature of the case, different from speech between man and wife, between friends, between teacher and pupil, government and subject, friend and foe, and in each case the truth which this speech conveys is also different.

Telling the truth is then a matter of learning discrimination. It is a matter of sensitive appreciation of the demands of real situations and fidelity to the people involved in it. The example Bonhoeffer uses of the child forced into telling lies to protect his family when subject to interrogation by the police or a school teacher, is, he insists not a case of deceit, but the necessary use of secrecy to preserve the demands of truthfulness in situations of different kinds. We have here the paradox of the lie which is ultimately more truthful than the bare truth, because it attempts to safeguard the confidentiality of truth specific to each situation. If truthfulness in personal relationships is expressed in terms of 'fidelity to the demands of the situation' and 'responsibility to other people', then secrecy is intimately involved as a value implicit in truthfulness and deceit is in fact very rare and perhaps best exemplified by the cynic who is determined to 'tell the truth and be damned'.

Finally, there is a common kind of situation in which the rules of ordinary confidentiality may be called in question, the crisis of the confidential relationship involved in the death or suicide of the patient. Death highlights the limits of the doctor's confidence and perhaps underlines for him the fragmentariness of his knowledge and the failure of his art, especially in the case of premature death. However, death also represents something metaphysical which points to the ultimate boundaries of human experience and raises questions about the significance of human life and the meaning of the human condition. As such, it may be that in the face of death, doctor and patient need to re-examine the pre-suppositions of privacy, confidence and secrecy on which the confidential relation is based? Is the intense difficulty and anxiety experienced by doctors in communicating bad prognoses related t $\overline{\bar{\sigma}}$. their own unwillingness to penetrate the secrets of: death with the dying in the kind of truthfulnes $\overrightarrow{\bar{s}}$ which involves both fidelity to the demands of this new and unique situation and responsibility to the patient as person faced with a unique and un repeatable life crisis?

\section{References}

${ }^{1 B r i t i s h}$ Medical Association (1974). Medical Ethicsô London, BMA House, Tavistock Square, pp I-2, 13 ${ }^{2}$ British fournal of Psychiatry (October 1976), News an $\Phi$ Notes: Confidentiality: A Report to Council, Roydur College of Psychiatrists.

${ }^{3}$ Friedson, E (r970/75). Profession of Medicine, New York. Dodd Mead \& Company. Chapter I. 일

${ }^{4}$ British Medical Association (1974). Medical Ethics, p 13. ${ }^{5}$ Ibid, $\mathbf{p} 13$.

Ibid, pp 17-18. Cf. British Medical fournal (27 Jan 1973), pp 213-216, Medical Research Council? Responsibility in the Use of Medical Information in Research.

'Bonhoeffer, D (1955). Ethics, London. SCM Press: pp 145-147.

${ }^{8}$ Robitscher, J B (1967). Public Life and Private In formation, fournal of the American Medica Association, Oct 30, 202, 5.

'Balint, M (1957/74). The Doctor, his Patient and the Illness. London. Pitman Medical. pp II-18.

${ }^{10}$ Friedson, E (1970/75). Op. cit. p 322.

11Shenkin, B N and Warner, D C (1973). Giving the Patient his Medical Record: A Proposal to Improve the System, New England fournal of Medicines. 27 Sept, pp 688-692. Cf. American Psychiatrie Association (1972). Position Statement on the Need for Preserving Confidentiality of Medical Records in Any National Health Care System, Americam fournal of Psychiatry, 128, 10 April.

${ }^{12}$ British Medical fournal (Editorial) (20 March 1971)

A Case of Confidence.
${ }^{13}$ British Medical fournal (23 June 1973). New Horizons in Medical Ethics.

${ }^{14}$ British Association of Social Workers (1971). Con fidentiality in Social Work, London. Discussion Paper No I, BASW Publications, The Oxford House, Derbyshire Street, E2 6HG.

${ }^{15}$ Bonhoeffer, D (1955), op. cit. pp 326-334. 